\title{
Giant Peritoneal Loose Body in the Pelvic Cavity
}

\author{
Joung Teak Jang, Haeng Ji Kang', Ji Young Yoon², Seo Gue Yoon \\ Departments of Surgery, ${ }^{1}$ Pathology, and ${ }^{2}$ Radiology, Seoul Song Do Hospital, Seoul, Korea
}

We report a case of a large peritoneal loose body diagnosed on computed tomography. The most common causes of a peritoneal loose body are thought to be torsion and separation of the appendices epiploicae. Peritoneal loose bodies are usually small, 0.5 to $2.5 \mathrm{~cm}$ in diameter. However, "giant" peritoneal loose bodies, larger than $4 \mathrm{~cm}$ in diameter, are an uncommon disease and present with various symptoms, and are difficult to diagnose preoperatively. Especially, abdominal large peritoneal loose bodies are frequently misdiagnosed as tumorous disease preoperatively. In our case, the loose body appeared as a round pelvic mass with central calcifications and a distinct fat plane separating it from adjacent organs. Preoperatively, we suspected a tumorous lesion from the wall of the upper rectum; however, at laparoscopy, a large peritoneal loose body was detected. An extraction of the giant peritoneal loose body was performed laparoscopically.

Keywords: Peritoneal loose body; Appendices epiploicae; Laparoscopic surgery

\section{INTRODUCTION}

An intra-abdominal loose body is sometimes observed during laparotomy or autopsy [1]. In most cases, it has a diameter of about 0.5 to $2 \mathrm{~cm}[2,3]$. A case of an intra-abdominal loose body that was observed in a Korean pediatric patient was reported in 2009 [4]. Some intra-abdominal loose bodies are believed to occur because of adnexal torsion and separation due to the torsion and separation of epiploic appendages [5-8]. Researchers speculate that such small loose bodies grow to giant loose bodies due to intra-abdominal retention of body fluids [5-9].

A giant loose body with a size of more than $4 \mathrm{~cm}$ in diameter is very difficult to diagnose before surgery and is rarely diagnosed and reported in clinical practices [10]. Until now, no such case has been reported in Korea. Discrimination between a giant loose body and a tumor or an intra-abdominal foreign body is required before the diagnosis can be confirmed [3]. Although a giant loose

Received: June 22, 2011 - Revised: July 18, 2011

Accepted: July 19, 2011

Correspondence to: Seo Gue Yoon, M.D.

Department of Surgery, Seoul Song Do Hospital, 72 Dasan-ro, Jung-gu,

Seoul 100-830, Korea

Tel: +82-2-2231-0900, Fax: +82-2-2233-8528

E-mail:seogue@nate.com

(c) 2012 The Korean Society of Coloproctology

This is an open-access article distributed under the terms of the Creative Commons Attribution NonCommercial License (http://creativecommons.org/licenses/by-nc/3.0) which permits unrestricted noncommercial use, distribution, and reproduction in any medium, provided the original work is properly cited. body is a rare lesion, careful consideration of this disease could be useful for the diagnosis and treatment of intra-abdominal lesions that show irregular findings.

The authors conducted an explorative laparotomy on a patient who was suspected of having a stromal tumor or teratoma before surgery and experienced a case of giant loose body with a size of $4.5 \times 4.5 \times 3 \mathrm{~cm}$. Accordingly, that case is reported in this paper.

\section{CASE REPORT}

A 60-year-old healthy male patient who had no previous history of disease or medication visited the Seoul Song Do hospital for a regular medical examination. The patient had dyspepsia, but did not complain of abdominal pain and other digestive symptoms such as anorexia, nausea, vomiting, and diarrhea. As a result of computed tomography (CT), an oval-shaped lesion with calcification of the luminal core was observed (Fig. 1). The result of magnetic resonance imaging (MRI) showed a lesion with a size of approximately $4 \mathrm{~cm}$ that shared a margin with the rectum and that had signal intensity similar to that of nearby muscle tissues, appearing as a lesion with low intensity in the T1- and the T2-weighted images (Fig. 2).

Based on the aforementioned radiological information, a suspected stromal tumor, leiomyoma or teratoma with calcification of the core originating from the rectal wall was diagnosed. Accordingly, the patient underwent laparoscopic surgery. As a result of the surgery, a hard oval-shaped giant loose body that was completely separated from the intrapelvic cavity was found (Fig. 3). 
Volume 28, Number 2, 2012

Journal of The Korean Society of

Coloproctology

The loose body was white, had an elliptical shape with a size of 45 $\times 40 \times 30 \mathrm{~mm}$, and had a slightly hard surface (Fig. 4). Histologically, it included central fat necrosis tissues over which fibrosis tissues had formed as a thin layer (Fig. 5).

\section{DISCUSSION}

Peritoneal loose body intra-abdominal loose body is sometimes accidentally found during surgery or autopsy [2]. Loose bodies are generally very similar to each other, being white or gray with a soft and light margin and having a density similar to that of rubber [11]. In some cases, it is found as a calcified form. In general, it has a diameter of about 0.5 to $2.5 \mathrm{~cm}$ and is freely separated from the inside of the abdominal cavity. However, a loose body with a size of approximately $45 \mathrm{~mm}$ is very rare. Despite such a large size, it can be easily removed by laparoscopy without injury

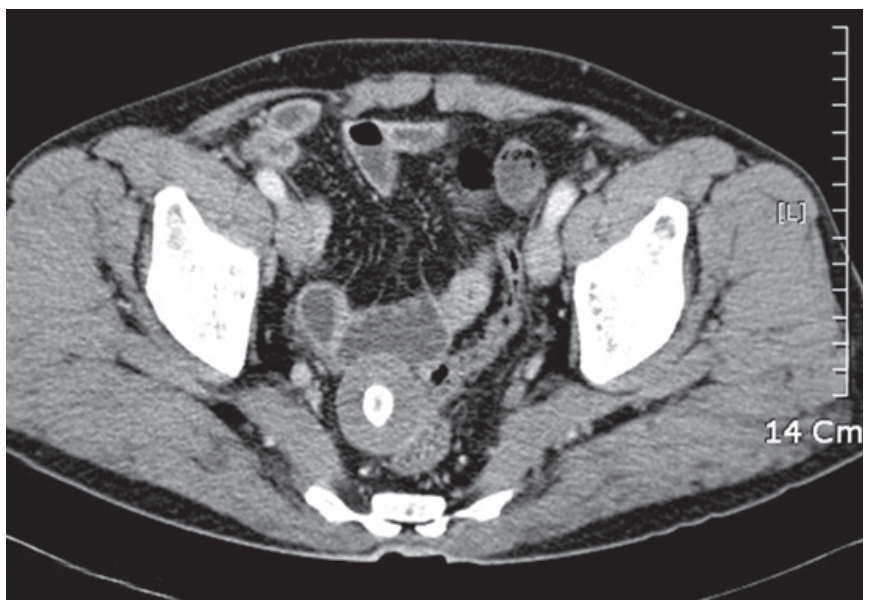

Fig. 1. Contrast-enhanced computed tomographyt of the abdomenpelvis showing a central calcified oval mass in the pelvis.
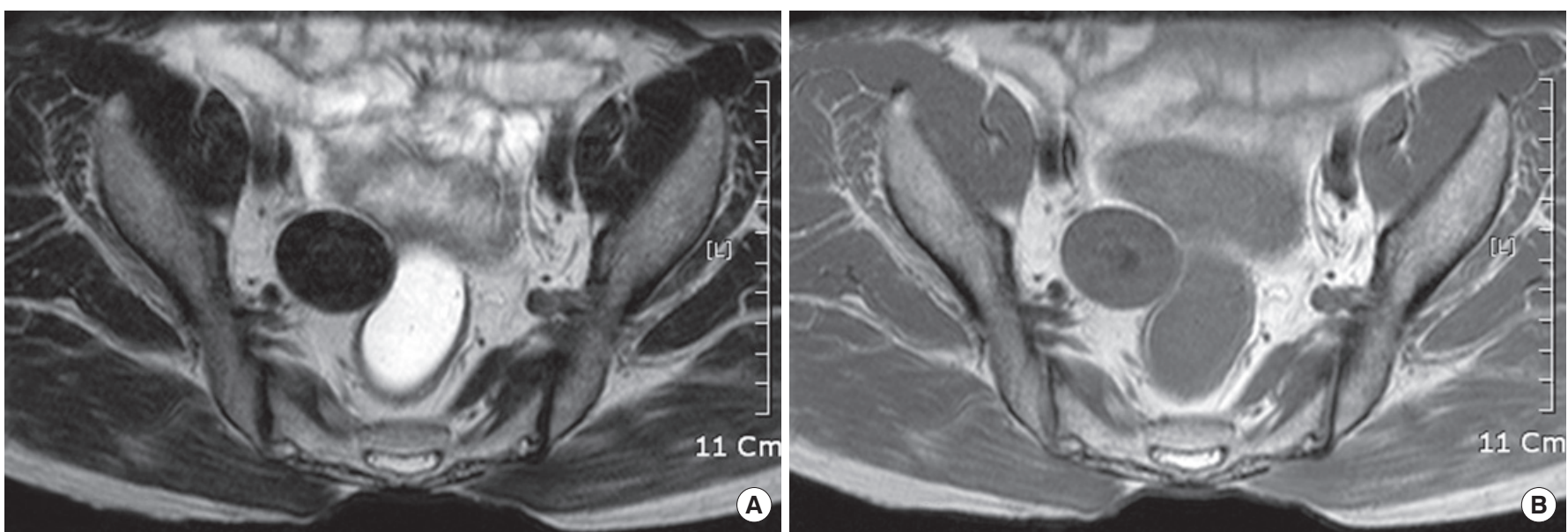

related to the surgery.

In general, an intra-abdominal loose body is thought to be formed due to the torsion and separation of epiploic appendages $[5,6]$. The torsion, strangulation, and necrosis of epiploic appendages may occur due to inflammation caused by intra-abdominal adhesion, volvulus, intestinal obstruction, or intestinal perforation. Except for a loose body that has undergone normal calcification, no particular pathological importance is found, and no pathology or frequency data are available. However, in some cases, an intraabdominal loose body has been reported to cause symptoms such as abdominal pain or dyspepsia. In addition, in severe cases, clinical symptoms such as intestinal obstruction may occur [12]. The loose body of the patient in this case report is thought to have been formed by epiploic appendages in the intra-abdomen and to have gradually grown to $45 \mathrm{~mm}$ with inflammation, but its exact pathogenesis was unclear.

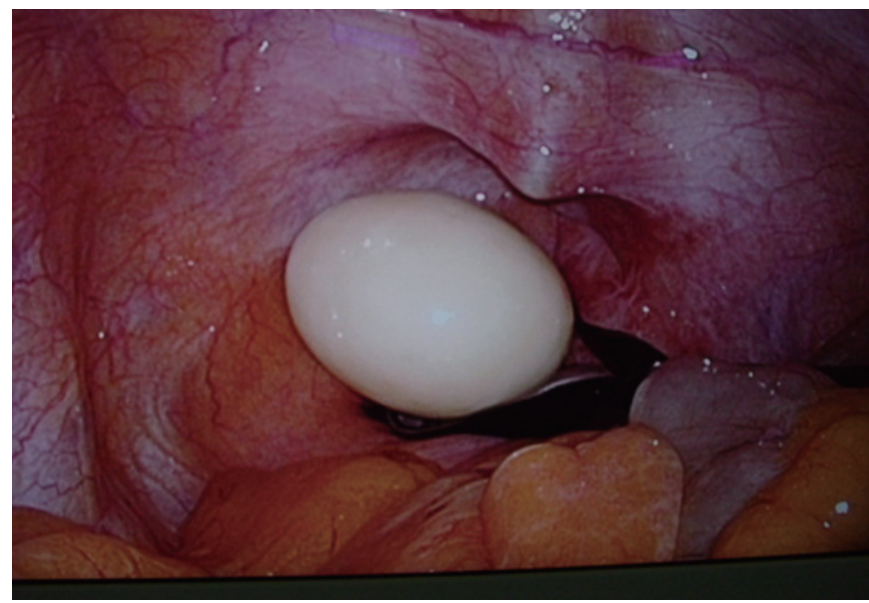

Fig. 3. Intraoperative laparoscopic view shows egg shaped mass.

Fig. 2. Pelvis magnetic resonance images. A well defined dark mass is near the pelvis in a T1-weighted sequence, suggestive of calcification and lesions appears to be a signal such as a muscle. 


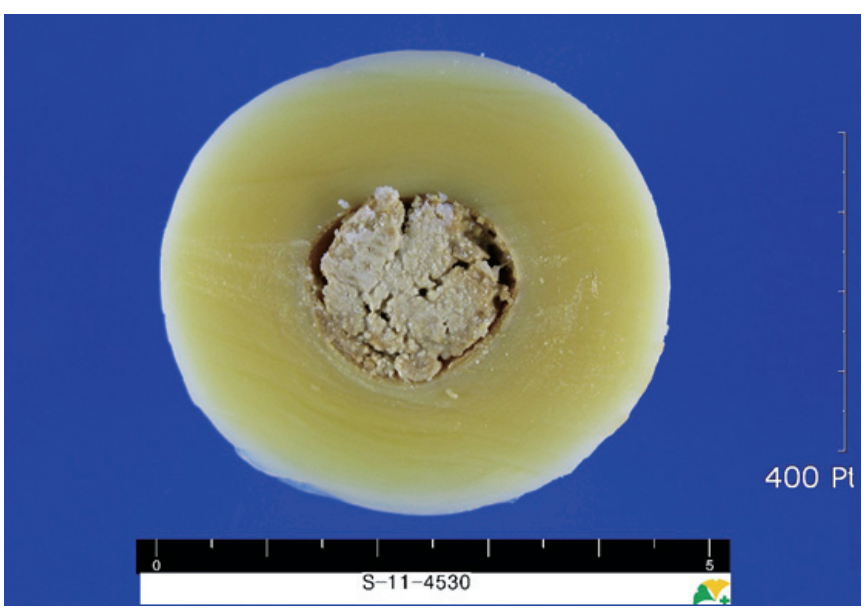

Fig. 4. The loose body appeared as a round pelvic mass with central calcifications and a distinct fat plane separating it from adjacent organs.

The discrimination of an intra-abdominal giant loose body from other lesions such as rhabdomyomas, fibrous tumors, desmoid tumors, teratomas, ovarian metastases, urinary stones, gallstones, appendicitis, or calcified lymph nodes is important [3], and CT or MRI can be used for that purpose. In the case of a leiomyoma, it consists of muscle tissues or collagen fiber and has a low signal intensity in the T1- and the T2-weighted images of MRI. Due to this, the discrimination of a leiomyoma from an intra-abdominal loose body is difficult. However, CT is somewhat useful in the process of discrimination because contrast enhancement is achieved in a leiomyoma and a teratoma, but not in a loose body. In addition, an intra-abdominal giant loose body has a homogenous internal region, which is also helpful for discrimination. In microscopic examinations, fat necrosis tissues or calcified tissues that seem to originate from the necrosis of epiploic appendages are sometimes observed in the core of the intra-abdominal loose body. Those tissues are thin and fibrosis, do not have cellular components, and surround the central region.

In most cases, an intra-abdominal loose body is accidentally found as a lesion with a size similar to that of a small bean. If an irregular mass with calcification of the central region is found, a giant intraabdominal loose body should be suspected [13]. If a peritoneal loose body is suspected, position change imaging will be helpful for diagnosis. The diagnosis of a giant loose body is expected to reduce unnecessary surgical treatments for patients whose giant loose body has been accidentally found asymptomatically.

\section{CONFLICT OF INTEREST}

No potential conflict of interest relevant to this article was reported.

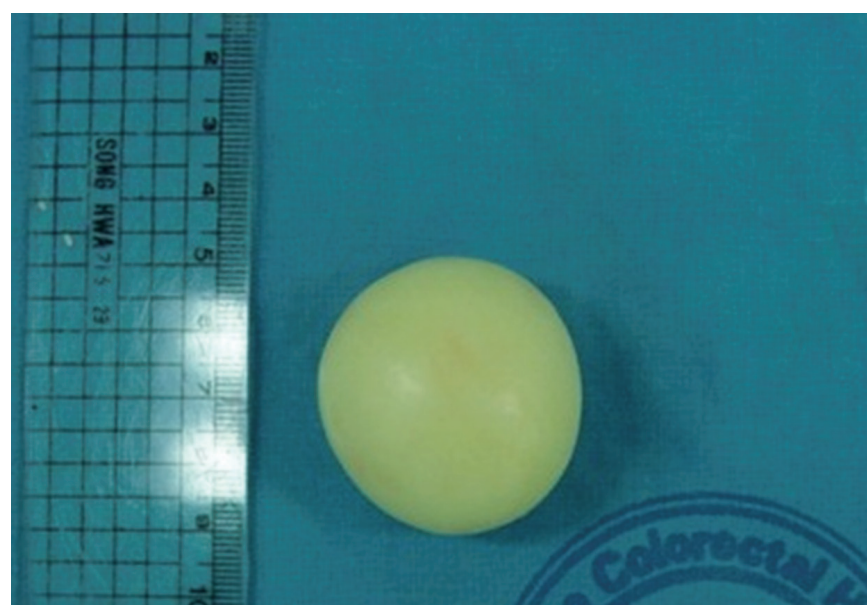

Fig. 5. The loose body appeared as a round pelvic mass.

\section{REFERENCES}

1. Southwood WF. Loose body in the peritoneal cavity. Lancet 1956; 271:1079.

2. Takada A, Moriya Y, Muramatsu Y, Sagae T. A case of giant peritoneal loose bodies mimicking calcified leiomyoma originating from the rectum. Jpn J Clin Oncol 1998;28:441-2.

3. Sakiyama H, Ueno F, Yamasaki K. Intraabdominal loose bodies considered to ble calculi in the genitourinary tract. Nishi Nihon Hinyokika 1983;45:111-3.

4. Shin SR, Choi DY. A case of peritoneal loose body in a child. Korean J Pediatr Gastroenterol Nutr 2009;12:75-8.

5. Desai HP, Tripodi J, Gold BM, Burakoff R. Infarction of an epiploic appendage. Review of the literature. J Clin Gastroenterol 1993;16: 323-5.

6. Patterson DC. Appendices epiploicae and their surgical significance with report of three cases. N Engl J Med 1933;209:1255-9.

7. Fieber SS, Forman J. Appendices epiploicae: clinical and pathological considerations; report of three cases and statistical analysis on one hundred five cases. AMA Arch Surg 1953;66:329-38.

8. Harrigan AH. Torsion and inflammation of the appendices epiploicae. Ann Surg 1917;66:467-78.

9. Koga K, Hiroi H, Osuga Y, Nagai M, Yano T, Taketani Y. Autoamputated adnexa presents as a peritoneal loose body. Fertil Steril 2010;93:967-8.

10. Mohri T, Kato T, Suzuki H. A giant peritoneal loose body: report of a case. Am Surg 2007;73:895-6.

11. Donald KJ, Kerr JF. Peritoneal loose bodies. Aust N Z J Surg 1968; 37:403-6.

12. Ghosh P, Strong C, Naugler W, Haghighi P, Carethers JM. Peritoneal mice implicated in intestinal obstruction: report of a case and review of the literature. J Clin Gastroenterol 2006;40:427-30.

13. Gayer G, Petrovitch I. CT diagnosis of a large peritoneal loose body: a case report and review of the literature. Br J Radiol 2011;84:e83-5. 